\title{
How clonal differences and within-tree heterogeneity affect pore properties of hybrid aspen wood and biochar?
}

\author{
Mika Turunen ${ }^{1}$ (1) - Fernando Urbano-Tenorio ${ }^{1} \cdot$ Kimmo Rasa $^{1}$ • Jari Hyväluoma ${ }^{2}$ • Peetu Rytkönen ${ }^{1}$ • Janne Kaseva ${ }^{1}$. \\ Egbert Beuker $^{1} \cdot$ Heikki Suhonen $^{3} \cdot$ Tuula Jyske $^{1}$
}

Received: 30 December 2020 / Revised: 10 March 2021 / Accepted: 23 March 2021 / Published online: 31 March 2021

(C) The Author(s) 2021

\begin{abstract}
Production of applicable and homogeneous biochar for soil amendment purposes would benefit from knowledge on how feedstock heterogeneity impacts key biochar pore properties and how the properties are transformed due to pyrolysis. This study aimed (1) to quantify how clonal differences and within-tree heterogeneity of a hybrid aspen feedstock (wood) impact biochar pore properties and (2) to estimate how pore properties of non-pyrolysed wood materials are transformed when pyrolysed into biochar. The study was conducted by collecting samples from a hybrid aspen (Populus tremula L. $\times$ Populus tremuloides Michx.) clonal field trial. Key pore properties of nonpyrolysed and pyrolysed wood samples were quantified with 3D X-ray imaging and quantitative image analyses. The results demonstrated how pyrolysis shifted distinctively bi-modal pore size distributions of the wood samples towards smaller pore size regions. The bi-modal wood tissue structure controlled the pore structure also in the biochars. Due to decreasing cell wall thicknesses, the pyrolysis increased the porosity of the materials. While the thermal process homogenized differences in the wall thicknesses, the thicknesses of the feedstock were also shown to control the resulting thicknesses in the biochars. Mechanisms of biochar pore property formation can be considered important when designing applicable biochars for a chosen purpose. Clonal differences and within-tree heterogeneity had a direct impact only on the wall thicknesses and the pore diameters of vessels. These impacts can be of interest when planning feedstock utilization in biochar production. However, the results suggest that relatively homogeneous biochar can be produced from hybrid aspen feedstocks.
\end{abstract}

Keywords 3D X-ray imaging $\cdot$ Microtomography $\cdot$ Poplar $\cdot$ Porosity $\cdot$ Wall thickness $\cdot$ Pyrolysis

Mika Turunen

mika.turunen@luke.fi

Fernando Urbano-Tenorio

fernando.urbanotenorio@luke.fi

Kimmo Rasa

kimmo.rasa@luke.fi

Jari Hyväluoma

jari.hyvaluoma@hamk.fi

Peetu Rytkönen

ext.peetu.rytkonen@luke.fi

Janne Kaseva

janne.kaseva@luke.fi
Egbert Beuker

egbert.beuker@luke.fi

Heikki Suhonen

heikki.suhonen@helsinki.fi

Tuula Jyske

tuula.jyske@luke.fi

1 Natural Resources Institute Finland (LUKE), Latokartanonkaari 9, 00790 Helsinki, Finland

2 Häme University of Applied Sciences, Mustialantie 105, 31310 Mustiala, Finland

3 Department of Physics, University of Helsinki, P.O. Box 64, 00014 University of Helsinki, Finland 


\section{Introduction}

Biochar is a porous and carbon-rich solid organic material resulting from the pyrolysis of bio-based feedstocks such as wood, crop residues, and manure [1]. Production of biochar has been estimated to have a high potential particularly regarding carbon sequestration and soil amendment purposes [2]. The applicability of biochars for different purposes has, however, still several open questions. While biochar can often enhance properties of an amended soil [3], biochar can also have adverse [4] or negligible [5] impacts on desired soil properties. While the choice of feedstock has been shown to control biochar applicability [6-8], heterogeneity in relevant properties within the feedstocks has been rarely studied. In addition to soil amendment applications, production of biochar with homogeneous properties can be of interest also to high-value end-uses such as energy storage purposes [9]. It would be beneficial to have understanding on how different factors control biochar properties and impacts, to predict their effects, and to be able to design applicable biochar products for different purposes and environmental conditions.

Pore structure of biochars is one of the key factors determining their impact as a soil amendment $[3,10]$. While the pore properties are affected by choices in the pyrolysis process (e.g., temperature and duration), they are generally more controlled by choice of the feedstock $[6,8,11,12]$. Particularly wood-based biochars have been found to have desirable properties in terms of porosity, pore size distributions, and surface area [6-8], while biochar produced from substances such as manure, sludge, and agricultural residue has often reported to have less suitable pore properties $[7,13]$. Therefore, from the point of view of pore properties, wood feedstocks can be of particular interest when producing an applicable biochar amendment. Furthermore, different wood characteristics have control on the pore properties of the biochars $[6,14]$. Regarding production of homogeneous biochar, it would be also central to estimate how heterogeneity in utilized wood feedstocks affects key biochar properties. However, these aspects have been previously largely unaddressed.

The optimal tree species for biochar production vary by location. In Finland and other similar high-latitude regions, hybrid aspen is one of the fastest growing species that can also easily be propagated vegetatively [15-17]. Therefore, studying the pore properties of hybrid aspen wood and biochar and related effects of feedstock heterogeneity would be essential from the point of view of fast production of applicable and homogeneous biochar in boreal conditions. Previous studies have shown significant differences in wood characteristics within hybrid aspen trees and between different clones [18]. However, the implications of the differences from the perspective of biochar pore properties remain unclear. The key affecting factors could be studied by quantifying key properties of non-pyrolysed and pyrolysed hybrid aspen wood samples.
Particularly, 3D X-ray imaging and quantitative image analysis methods have proven to be comprehensive tools to quantify pore properties of biochars and wood $[6,8,11,19]$. Since these methods can provide detailed information on pore properties (porosities, pore size distributions, cell wall thicknesses, etc.), they would also have the potential to unravel how pyrolysis mechanistically affects the pore properties. The information can be essential when predicting which raw materials are the most suitable for the production of applicable biochars. However, to our knowledge, quantitative analyses showing how the pore properties are transformed due to pyrolysis have not been previously conducted.

Based on the above premises, this study aimed to (1) estimate impacts of clonal differences and within-tree heterogeneity of a hybrid aspen wood feedstock on key biochar pore properties including pore size distributions, porosities, cell wall thicknesses, and mean pore diameters in key pore size regions and (2) quantify how pore properties of non-pyrolysed samples are transformed when pyrolysed into biochar. The study was conducted by collecting samples from a hybrid aspen (Populus tremula L. $\times$ Populus tremuloides Michx.) random-block designed clonal field trial. The key pore properties were analyzed using 3D X-ray imaging and quantitative image analyses.

\section{Materials and methods}

\subsection{Sample collection and preparation}

\subsubsection{Sample collection}

From a hybrid aspen $(P$. tremula $\mathrm{L} . \times P$. tremuloides Michx.) random-block designed clonal field trial in southeast Finland (P 61049', E 29020'), three clones were selected that had been included in wood property studies $[18,20,21]$ (Table 1 ). The trial was established in 2002 using one-year old plants. In February 2018, three trees from each clone were randomly selected (each tree from a different block) and felled.

Samples discs were collected from each tree from two different heights ( 1.3 and $5.0 \mathrm{~m}$ from the ground level) and three different radial locations within the sample discs (Fig. 1). This resulted in 45 different sampling locations describing clonal differences and within-tree heterogeneity of the feedstock (Fig. 1). The three tree individuals from each clone were considered as replicates when data was analyzed.

From each studied tree ( 3 trees per each clone), about 0.05 $\mathrm{m}$ thick sample discs were cut from $1.3 \mathrm{~m}$ and $5 \mathrm{~m}$ heights. The height of $1.3 \mathrm{~m}$ represented a standard height used when measuring and sampling trees in forestry. The height of $5 \mathrm{~m}$ was chosen as it represents about the highest level at which still two radial locations could be samples from all the studied trees. Samples $\left(20 \times 4 \times 4 \mathrm{~mm}^{3}\right)$ were thereafter excised from 
Table 1 Key mean characteristics of the hybrid aspen trees at the clone field trial

\begin{tabular}{lllllll}
\hline Clone no. $^{1}$ & $\begin{array}{l}\text { National } \\
\text { register ID }\end{array}$ & $\begin{array}{l}\text { Hytönen } \\
\text { et al. ID }\end{array}$ & $\mathrm{H}[\mathrm{m}]^{4}$ & LTL $[\mathrm{m}]^{5}$ & D1.3 [mm $]^{6}$ & D5.0 [mm $]^{7}$ \\
\hline 5 & C05-99-14 & 26 & $18.0 \pm 3.8$ & $5.2 \pm 1.8$ & $124 \pm 16$ & $104 \pm 28$ \\
4 & C05-99-34 & 20 & $18.9 \pm 2.1$ & $5.2 \pm 1.9$ & $141 \pm 12$ & $118 \pm 13$ \\
2 & C05-99-24 & 14 & $18.8 \pm 1.8$ & $5.7 \pm 5.0$ & $153 \pm 12$ & $129 \pm 12$ \\
\hline
\end{tabular}

${ }^{1}$ This ID is identical as in Korkalo et al. (2020), ${ }^{2}$ the national list of approved basic forest reproductive material, kept by the Finnish Food Authority, ${ }^{3}$ the ID used in Hytönen et al. $(2018 ; 2020),{ }^{4} H=$ tree height,${ }^{5} L T L=$ height of living treetop line measured from ground level, ${ }^{6,7}$ cross length (measured in north-south orientation) of sample discs from the heights of $1.3 \mathrm{~m}$ and $5.0 \mathrm{~m}$ from ground level three radial locations within the discs, specifically from the 1st-2nd, 5-6th, and 9-10th annual rings counting from the outermost layers, bark inwards (hereby called rings 1-2, 5-6, and 9-10, respectively). However, due to the age of the trees, ring 9-10 was not present at the height of $5 \mathrm{~m}$ and therefore samples were excised only from rings 1-2 and 5-6 at that height. The chosen heights and rings were considered to reasonably describe within-tree heterogeneity of the feedstock. It is, however, recognized that increasing sampling locations could further improve the accuracy of the estimate. Wood pore properties at different heights have been less intensively studied, but wood density and moisture content are known to vary by radial location and height [18], which supports the chosen approach. The samples were stored at $-20{ }^{\circ} \mathrm{C}$ until further processing.

\subsubsection{Sample preparation for fiber analyses and X-ray imaging}

The $20 \mathrm{~mm}$ long and $4 \mathrm{~mm}$ wide samples were excised from each frozen wood disc (45 samples in total; Fig. 1). For the fiber analyses, the samples were further split into match-sticksized specimens and macerated (i.e., fibers chemically separated) in a solution of glacial acetic acid and $50 \%$ hydrogen peroxide $(1: 1, \mathrm{v} / \mathrm{v})$ at $60{ }^{\circ} \mathrm{C}$ for over two nights (modified from Franklin [22]).

For 3D imaging with a micro-CT scanner, samples with the dimensions $8 \times 1.5 \times 1.5 \mathrm{~mm}^{3}$ were thereafter excised from the bigger samples. The samples were cut to include approximately $20-25 \%$ of latewood and $75-80 \%$ of earlywood whenever latewood was present in the samples to achieve representative samples of annual rings. Prior to imaging, the non-pyrolysed samples were dried in an oven for $48 \mathrm{~h}$ in $40{ }^{\circ} \mathrm{C}$.

\subsection{Pyrolysis}

Bench-scale batch-type pyrolysis equipment was used to pyrolyse the wood samples. The equipment consists of programmable indirect heating oven, airtight pyrolysis vessel with an internal temperature measurement system (TCC-K250-6.0-KY), water-jacket cooling system, and gas collection

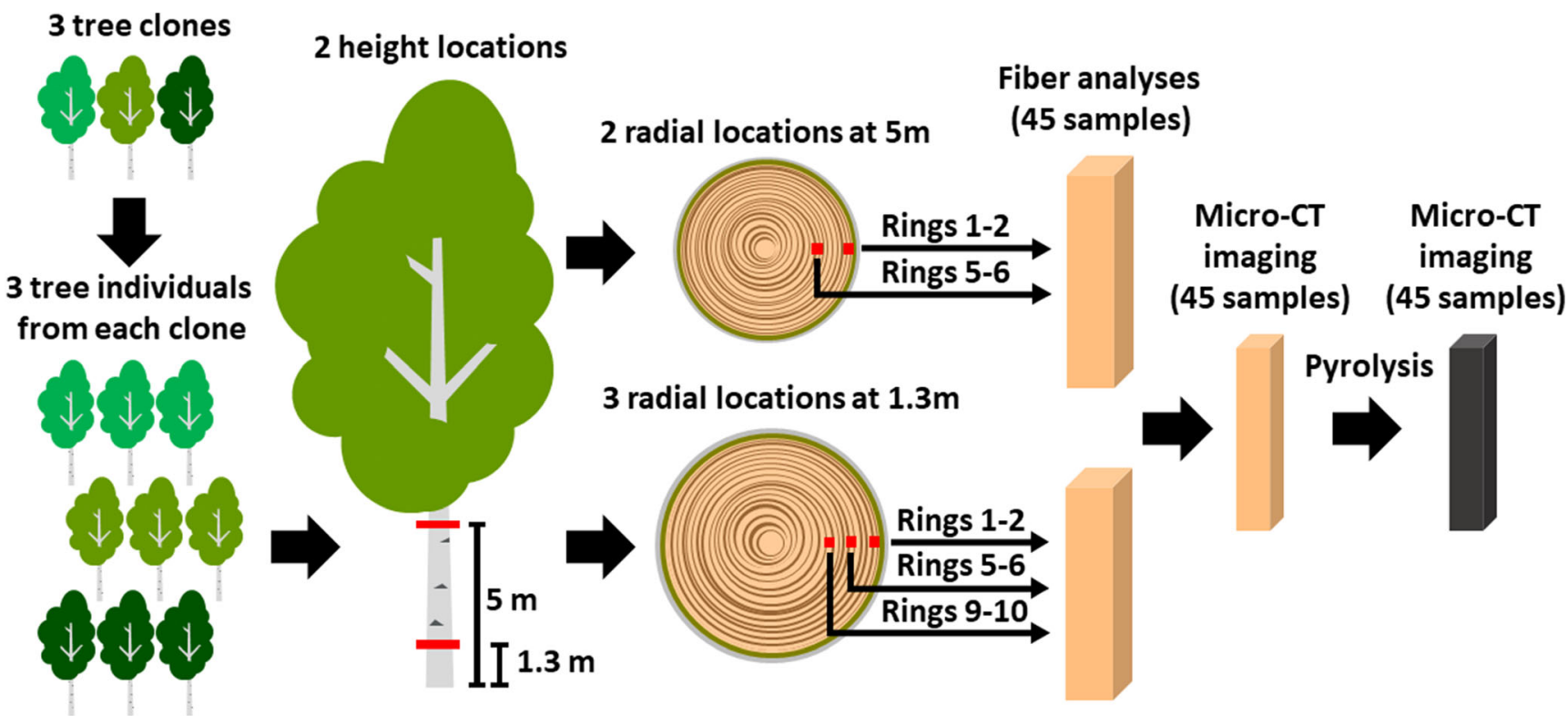

Fig. 1 A schematic overview of sample collection 
line (gas bag). The pyrolysis vessel was filled with bulk aspen wood ( 180 g, clone 2 from height 1.5-1.9 m). Each traceable aspen sample was placed into a ceramic crucible (individually) and crucibles were buried into the top-most layer of a bulk sample. Thus, the pyrolysis circumstances for samples and bulk material were as similar as possible and simultaneously, we secured that samples used in image analyses could be identified. Five parallel slow pyrolysis runs were performed. Before pyrolysis, the system was flushed with excess of $\mathrm{N}_{2}$ to remove air. No carrier gas was supplied during the experiment. During pyrolysis, temperature was raised with a rate of $1.8^{\circ} \mathrm{C} \mathrm{min}-1$ and maintained at $458 \pm 1$ ${ }^{\circ} \mathrm{C}$ for $60 \mathrm{~min}$. After cooling, biochar and liquid fractions were weighted and the volume of gas was determined by using a gas meter (Ritter). Char and liquid yields for the bulk sample were $26 \pm 0.6 \%$ and $51 \pm 0.4 \%$, and volume of gas fraction was $28 \pm 0.81$.

\subsection{D X-ray imaging and image analyses}

\subsubsection{Imaging}

The samples were 3D imaged by using an X-ray micro-tomography device (GE Phoenix Nanotom ${ }^{\circledR} 180$ NF, Wunstorf, Germany). The samples were glued to a carbon fiber rod sample holder with a cyanoacrylate glue $1.5 \mathrm{~h}$ before the scanning to prevent micromovements of the samples during the scan. For each $3 \mathrm{D}$ image, 1000 projections (full $360^{\circ}$ ) were conducted by using a source voltage of $60 \mathrm{kV}$, a source current of $240 \mu \mathrm{A}$ and exposure time of $500 \mathrm{~ms}$. The scanned volume had the dimensions of $1 \times 1 \times 1 \mathrm{~mm}^{3}$. To exclude sample boundaries from the images, the center of the scanned cube was set $3 \mathrm{~mm}$ (for non-pyrolysed samples) or $2.5 \mathrm{~mm}$ (pyrolysed samples) down from the top of each prepared sample. The center location was different for the non-pyrolysed and pyrolysed samples in order to scan approximately the same region on both times, as the samples shrank when pyrolysed (see Fig. 2c). The voxel size was $1 \mu \mathrm{m}$, which was assumed to be sufficient for describing the majority of the pore volume of the samples $[6,8]$. The projections were reconstructed into 3D-image stacks by using GE phoenix datos $\mid \mathrm{x} 2$ reconstruction software version 2.4.0 (Phoenix|XRay Systems \& Services GmbH, currently part of Waygate Technologies owned by Baker Hughes).

\subsubsection{D image processing and analyses}

First, a region interest of $500 \times 500 \times 500 \mu \mathrm{m}^{3}$ was cropped from each 3D image to exclude artifacts in the image border areas and to reduce computational demands of the analyses. Thereafter, the 3D image stacks were processed in 3D with the Fiji software [23, 24]. The noise levels of the 3D image stacks were lowered by using anisotropic filtering with edge detecting algorithms [25] (Canny edge). The filtered images were segmented into binary images describing pores and solid regions in the images [26] (IJ_Isodata). Thereafter, mathematical morphological opening operations were conducted to these using 3D ball element [27] (morphological filters

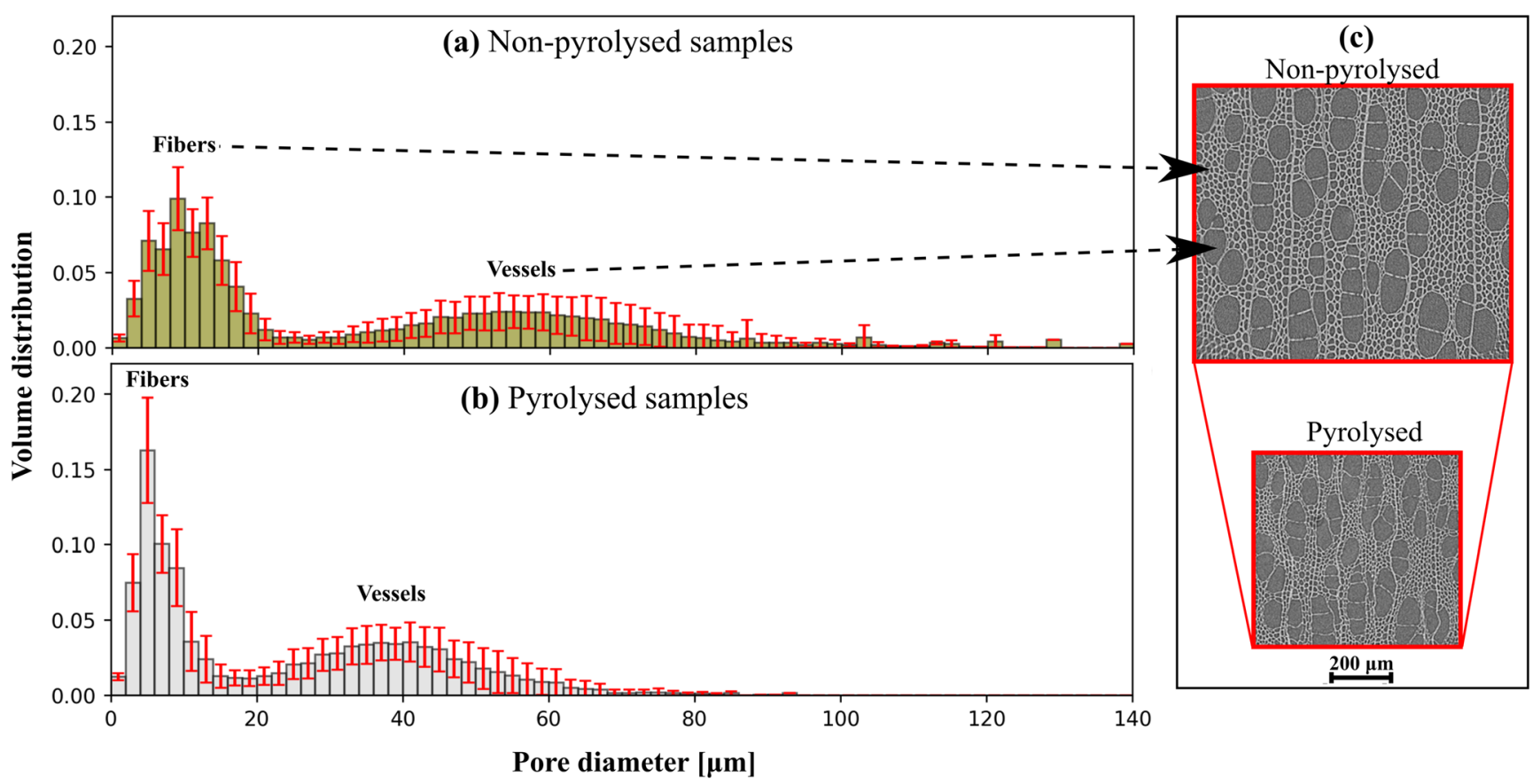

Fig. 2 Mean pore size distributions in all (a) non-pyrolysed and (b) pyrolysed hybrid aspen samples determined by $3 \mathrm{D}$ imaging and image non-pyrolysed and pyrolysed (shrunk) samples. The bars show the mean and the error bars denote the standard deviation 
(3D)). Finally, Fiji's Fill Holes-binary process was used to remove left over artifacts [23, 24]. The image processing stages are presented visually in Appendix Fig. 6.

After the image processing, porosities and pore size distributions were analyzed from the 3D images with the Fiji's Xlib-library's Pore Size Distribution plugin [28]. The mean diameters of fiber and vessel pores were determined from the pore size distributions by dividing the distribution at the minimum between the two modes and then calculating the means for both pore types. The volume fractions of fiber and vessel pores were similarly extracted from the pore size distribution by determining the area under the first and second modes, respectively.

Thereafter, pore wall thicknesses were determined using the segmented 3D images. The analysis algorithm was as follows. First, distance transform was determined using weighted Chamfer distance $\mathrm{d}_{3,4,5,7}$ with a rescaling procedure described in detail by Svensson and Borgefors [29]. In the distance transform, each solid voxel was labeled with its closest distance to solid-void interface. Then we determined a medial surface for the solid phase utilizing the unidirectionality of the wood structure and skeletonizing each layer perpendicular to the void direction using a thinning operation derived from hit-or-miss transform (see [30]). Wall thickness distribution was then determined from the distance values at the voxels belonging to the medial surface.

\subsection{Fiber analyses}

The physical dimension of fibers including average length, fiber width, and cell wall thickness was characterized by using a Kajaani FiberLab fiber analyzer (Valmet Automation, Finland). The principle of fiber length measurement of the device is in accordance with TAPPI T271 standard and is described in Reyier Österling et al. [31].

The macerated fiber samples with approximately $15 \%$ solid content were stored in plastic bags in a refrigerator. Circa $0.6 \mathrm{~g}$ of a sample was inserted and diluted to $200 \mathrm{ml}$ of water and disintegrated in a FiberLab manual defibrator to separate the fibers from each other. After disintegration, the sample was further diluted to 21 and mixed. A glass pipette with a widened opening was used to withdraw a $30 \mathrm{ml}$ sample, corresponding to circa 20,000 fibers, which was inserted into a Kajaani FiberLab sample vessel for automatic measurement. Each fiber sample was measured in duplicates.

\subsection{Statistical analyses}

All dependent variables (mean pore diameters, porosities, pore volume fraction in fibers, cell wall thickness, and ratio of pyrolysed to non-pyrolysed wall thickness) were analyzed by a linear mixed model (LMM) having clone (5, 4, and 2$)$, height (1.3 $\mathrm{m}$ and $5 \mathrm{~m}$ ), ring (1-2, 5-6, and 9-10), pyrolysis (non-pyrolysed and pyrolysed), and all of their interactions as fixed effects. Correlated samples of pyrolysis were taken account through the G-side random effect, and the correlations between rings from the same height within same experimental unit were taken into account by using a homogeneous compound symmetry (CS) structure through the R-side random effect. For the FiberLab measurements, a simplified model was used, where the fixed effect of pyrolysis and, thus, also the G-side random effect was omitted.

The assumption of normality of residuals was graphically studied from multiple residual plots and found adequate. Restricted maximum likelihood estimation (REML) method was used for the LMMs, and the degrees of freedom were calculated using the Kenward-Roger method [32]. The stepdown method of Westfall [33] was used for pairwise comparisons of means, with a significance level of $\alpha=0.05$. All non-meaningful cross-comparisons (e.g., clone 2 in height 1.3 $\mathrm{m}$ vs. clone 4 in height $5 \mathrm{~m}$ ) of the significant interaction terms were excluded to minimize the amount of pairwise comparisons.

The analyses were performed using the GLIMMIX procedure of the SAS Enterprise Guide 7.15 (SAS Institute Inc., Cary, NC, USA).

\section{Results}

\subsection{Pore size distributions}

Bi-modal pore size distributions were a distinct feature of the non-pyrolysed and pyrolysed materials (Fig. 2a-b). The two key pore size regions originated from the wood tissue structure (Fig. 2c). The pore volume of the materials resided in two distinct size classes within fibers and in vessels as shown in Fig. 2c. For simplicity, the pore size regions are hereby called fibers and vessels. The pyrolysis of the studied materials affected the pore structure by shifting the distributions towards the small pore size classes and consequently concentrating the distributions to a narrower range of pore size classes (Fig. 2ab). The narrowing range of the pore size classes was explained by the shrinkage of the materials due to the pyrolysis, as exemplified visually in Fig. 2c.

The pyrolysis systematically reduced the mean pore diameters in both the fibers and the vessels in all studied materials ( $p<0.01$; Fig. 3a-b). In the fibers, the mean pore diameter was reduced on average $34 \%$ (from 12 to $8 \mu \mathrm{m}$ ). For the vessels, the corresponding reduction was from 55 to $39 \mu \mathrm{m}$ (29\%). Regarding the mean pore diameters of the vessels, a significant difference $(p=0.03)$ was also detected between the different clones (Fig. 3b) with mean diameters varying between 52 and $59 \mu \mathrm{m}$. No other statistically significant differences were found regarding the mean pore diameters. 

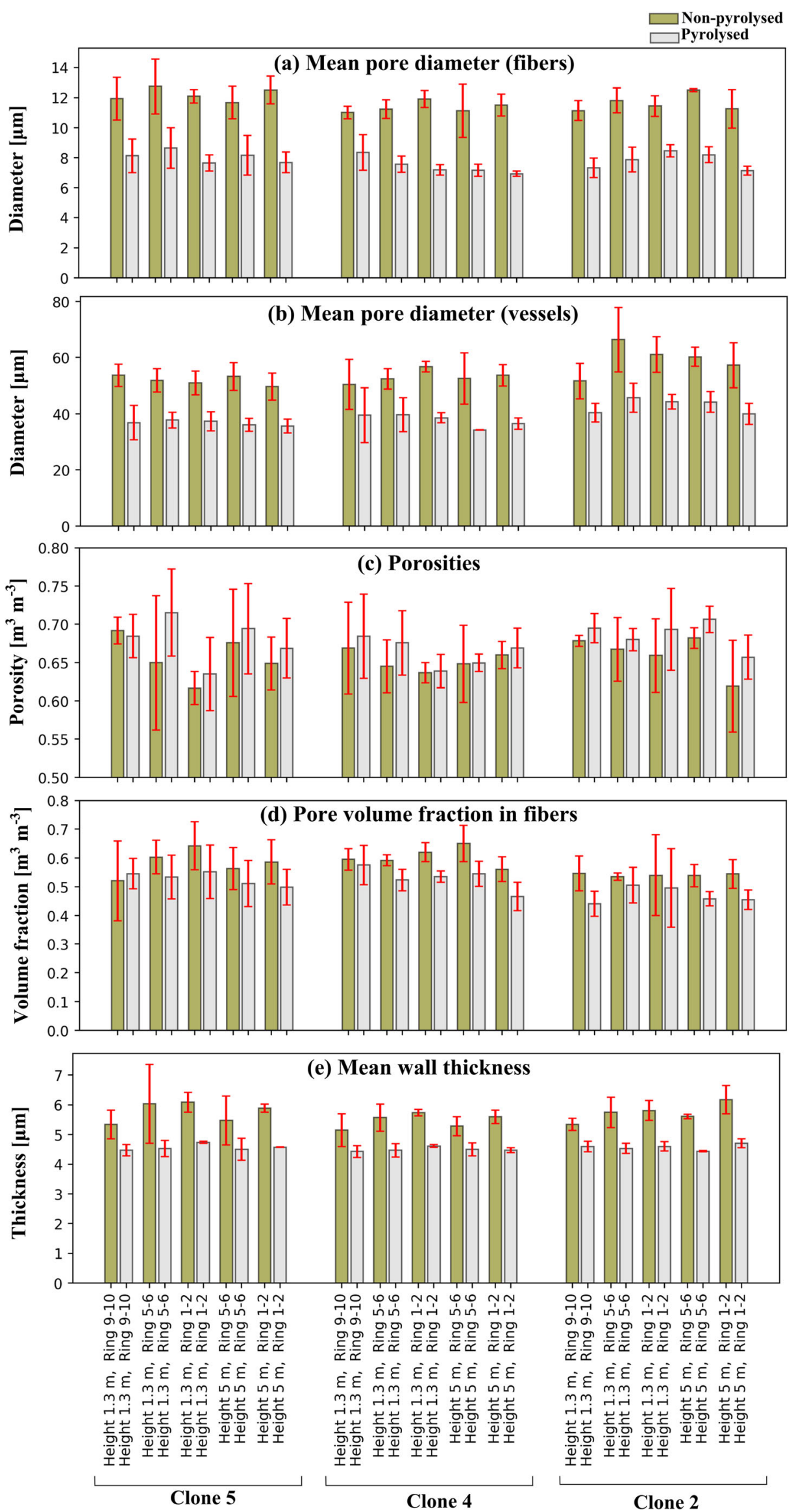
Fig. 3 (a) Mean pore diameters in fibers, (b) mean pore diameters in vessels, (c) porosities, (d) pore volume fraction (of total imaged porosity) in fibers, and (e) cell wall thickness of pyrolysed and nonpyrolysed hybrid aspen samples. The bars show the mean and the error bars denote the standard deviation among the three tree individuals

\subsection{Pore volumes}

Despite the reductions in the mean pore size diameters, pyrolysis systematically increased the pore volumes of the samples in all studied cases, with only one exception (Fig. 3c). Pyrolysis was the only factor causing statistically significant differences between the pore volumes $(p<0.01)$. On average, the porosity was 0.66 (standard deviation $\sigma=0.05$ ) in the nonpyrolysed samples and $0.68(\sigma=0.04)$ in the pyrolysed ones.

To assess how the pyrolysis affected the two key pore size regions (fibers and vessels), it was also analyzed how the total imaged pore volume was distributed among them before and after the pyrolysis. The pyrolysis systematically reduced the pore volume share in fibers and consequently increased the fraction in vessels, with only one exception (Fig. 3d). The pyrolysis was the only factor causing significant differences in the fraction of pores in fibers and vessels $(p<0.01)$. Prior to the pyrolysis, the mean pore volume fraction in fibers and vessels (calculated as pore volume shares under the two distinct pore size distribution modes) was $0.58(\sigma=0.08)$ and $0.42(\sigma=0.08)$, respectively. After the pyrolysis, the mean pore volume share of fibers was $0.51(\sigma=0.08)$ and that of vessels was $0.49(\sigma=0.08)$.

\subsection{Pore wall thicknesses and fiber characteristics}

The cell wall thickness determined with the 3D image analyses differed by both pyrolysis (pyrolysed vs. non-pyrolysed; $p<$ $0.01)$ and ring $(p=0.03)$. There was also a two-way interaction between these two factors, i.e., the impact of a ring was dependent on pyrolysis $(p<0.01)$. The pyrolysis systematically reduced pore cell wall thickness in all studied materials (Fig. 3e). On average, the thickness was $5.7 \mu \mathrm{m}(\sigma=0.6 \mu \mathrm{m})$ in the nonpyrolysed samples and $4.5 \mu \mathrm{m}(\sigma=0.2 \mu \mathrm{m})$ in the pyrolysed samples. Regarding the non-pyrolysed samples, all rings differed from each other ( $p \leq 0.04$; Fig. 3e). The mean values ranged from 5.3 to $5.9 \mu \mathrm{m}$ between the different rings. The cell wall thickness was the highest in ring 1-2 and the lowest in ring 9-10. No differences were found in the cell wall thickness between the rings of the pyrolysed samples ( $p \geq 0.32$ ).

The ratios of pyrolysed to non-pyrolysed cell wall thicknesses (Fig. 4a) were analyzed to decipher if the wall thicknesses in the non-pyrolysed materials controlled the resulting wall thicknesses in the biochars. The ratios were found to differ only by ring $(p<0.01)$, and only ring 9-10 differed from the other rings. The cell wall thickness decreased the most in ring 1-2 (mean ratio $0.79, \sigma=0.03$ ), while the decrease was the smallest in ring 9-10 (mean ratio 0.86, $\sigma=0.05$ ). Despite the differences in the ratios between the rings, the wall thickness of all non-pyrolysed and pyrolysed samples also correlated (Pearson's $R 0.78, p<0.01$; Fig. 4b).

The mean fiber cell wall thicknesses (non-pyrolysed) measured with the FiberLab analyzer $(6.3 \mu \mathrm{m}, \sigma=0.6 \mu \mathrm{m}$; Fig. 5 a) corresponded with the cell wall thicknesses determined with the 3D image analyses $(5.7 \mu \mathrm{m}, \sigma=0.6 \mu \mathrm{m}$; Fig. 3e). Similarly to the 3D imaged wall thickness, the fiber cell thickness differed only by ring $(p<0.01)$. Practically, the differences were small with the mean values from $5.9 \mu \mathrm{m}$ to $6.4 \mu \mathrm{m}$ (Fig. 5a), similarly as in the wall thickness determined with the $3 \mathrm{D}$ image analyses.

The fiber length (Fig. 5b) differed only by ring and height $(p<0.01)$. Regarding the rings, the differences were marked with mean values of $836 \mu \mathrm{m}(\sigma=51 \mu \mathrm{m}), 726 \mu \mathrm{m}(\sigma=72$ $\mu \mathrm{m})$, and $612 \mu \mathrm{m}(\sigma=49 \mu \mathrm{m})$ for rings $1-2,5-6$, and 9-10, respectively. The trend of increasing fiber length from the pith to the bark was qualitatively similar for each clone. The means were $754 \mu \mathrm{m}(\sigma=115 \mu \mathrm{m})$ and $738 \mu \mathrm{m}(\sigma=81 \mu \mathrm{m})$ for heights $1.3 \mathrm{~m}$ and $1.5 \mathrm{~m}$, respectively. The fiber widths differed only by clone $(p=0.03)$ and practically the differences were minor (Fig. 5c).

\section{Discussion}

\subsection{Pore size distribution, pore volume, and wall thickness}

The bi-modal pore size distributions resembled the distributions found in other deciduous wood-based biochars $[6,8]$. Previously, Rasa et al. [8] and Turunen et al. [6] determined the pore structure of willow biochars with 3D X-ray image analyses and reported local maxima to reside around the diameters $8-10$ and 30-50 $\mu \mathrm{m}$. In the current study, the maxima of the diameters in the pyrolysed hybrid aspen samples were around 8 and $39 \mu \mathrm{m}$ and thus corresponded with the willow studies. For reference, Kameyama et al. [7] reported pore size ranges around $1 \mu \mathrm{m}$ to dominate in agricultural residue and $1-$ $10 \mu \mathrm{m}$ in wood-based biomasses. While the pore size distributions of different wood species [34] and different types of chars have been reported previously, pore size distributions of non-pyrolysed feedstock and pyrolysed biochars have been rarely quantitatively compared. Our results demonstrated how the pore diameters systematically shifted towards smaller pore size regions due to the pyrolysis (Fig. 2, 3a-b). The wood tissue structure of the samples clearly controlled the pore size distributions also after pyrolysis, as demonstrated previously $[6,8,7,11,35,36]$.

To our knowledge, pyrolysis impact on the mean pore diameters and the distribution of pore volume to the key pore size regions has not been reported previously. The pore 
Fig. 4 (a) Ratios of pyrolysed to non-pyrolysed pore cell wall thickness in the studied hybrid aspen wood samples. The bars show the mean and the error bars denote the standard deviation among the three tree individuals. (b) Relationship between the wall thickness of pyrolysed and nonpyrolysed samples. The red line denotes the linear regression
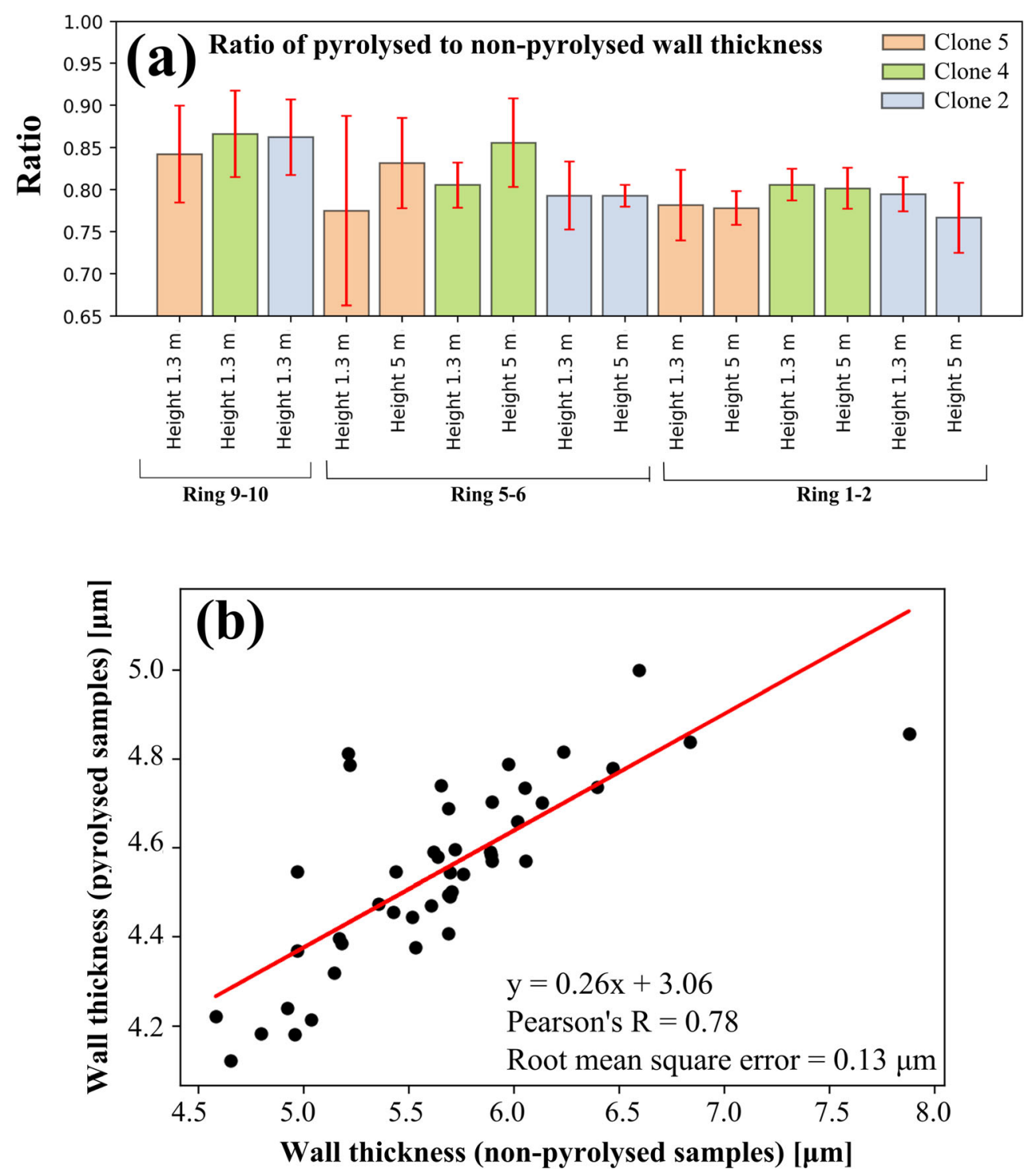

volume distribution is central from the point of water retention and plant available water. In the current study, the pore volume share of readily plant available water (pore diameters 1$30 \mu \mathrm{m}$, Fig. 2) was on average 0.59 in the non-pyrolysed samples and 0.63 in the pyrolysed samples. Thus, from the point of view of plant water availability, the pyrolysis process improved the water retention properties of the non-pyrolysed samples. Previously, Spokas et al. [37] did not find marked differences between the impacts of non-pyrolysed and pyrolysed pine chip amendments on hydraulic properties of sandy soils, even though both of the amendments increased soil water content at saturation. However, biochar impacts on soil properties consist of several mechanisms $[12,36]$. Therefore, quantification of pore property transformation due to pyrolysis can improve the understanding on how biochar effects on soil properties differ from those of non-pyrolysed materials.
Due to the decreasing mean pore diameters, it could be expected that the porosity of the samples would decrease when pyrolysed, but the porosities increased (Fig. 3c). Based on previous studies $[8,11]$, nanoporosity of our samples can be considered negligible. Based on those studies and our results (Fig. 2), the systematic pore volume increase despite the decreasing mean pore diameters (in the current study) can be attributed to the decreased pore cell wall thickness, rather than generation of small pores within the walls. The systematic increases in the porosities demonstrated that in terms of volume, the cell wall thicknesses decreased more than the pore diameters. Our unpublished results (Rasa et al., unpublished data) showed similar results regarding willow materials. Knowledge on how pore characteristics of different feedstocks are transformed when pyrolysed into biochars can aid in choosing an optimal biochar raw material based on the feedstock properties. While the current study demonstrated 
Fig. 5 Measured (a) fiber cell aspen samples. The bars show the mean and the error bars denote the standard deviation among the three tree individuals
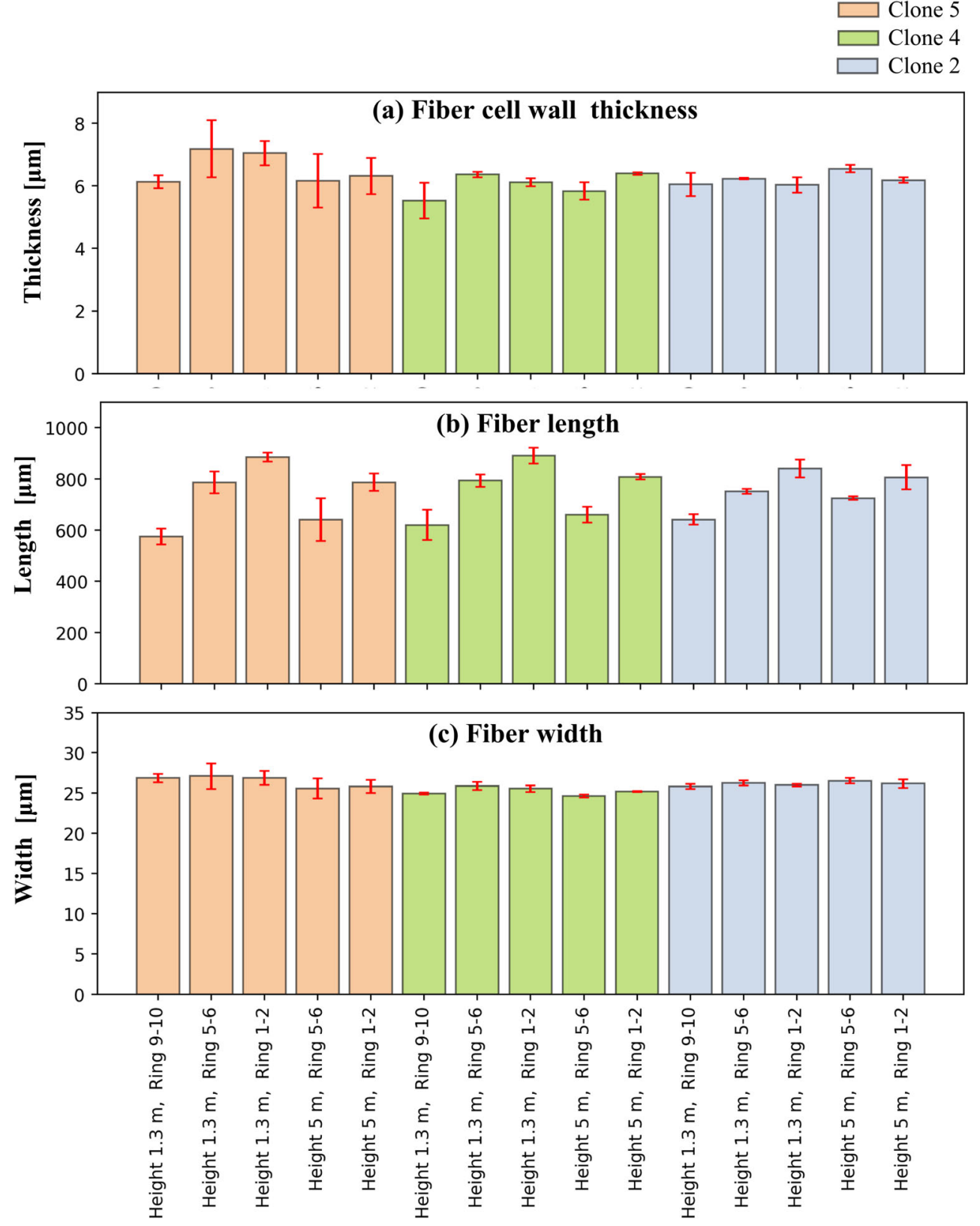

the mechanisms regarding the hybrid aspen samples, studies assessing these processes in a range of wood species would be needed to draw more general conclusions.

Porosity is one of the key factors determining biochar impact in end-use applications [3]. While our study reported the impacts of the chosen pyrolysis approach (Section 2.2), it could be argued that the pore transformation processes can be controlled by the choice of pyrolysis parameters. Pyrolysis production temperature has been found to have the most dominant impact on several biochar properties [38]. Pyrolysis has distinctly different impacts on different pore size classes, notably micrometer-range and nano-scale pores [12]. Micrometer-range pore space is not sensitive to pyrolysis temperature $[11,12]$. Nano-scale pores are more sensitive to pyrolysis temperature [12, 39], but nanoporosity of our samples can be considered negligible $[8,11]$. Note that the commonly applied the Brunauer-Emmett-Teller method describes only nanoscale pore structure [36]. Thus, choosing a feedstock which has appropriate pore properties can be considered essential when designing an applicable biochar for a particular end-use [11]. Our results provide rare insight on pore properties within hybrid aspen wood and biochar, which can be useful regarding such choices. It is, however, noteworthy that sufficient pyrolysis temperature is markedly important from the point of view of hydrophobicity reduction [12]. 


\subsection{Impacts of clonal differences and within-tree heterogeneity}

One previously largely unaddressed question is how heterogeneity of different feedstocks affects homogeneity of the resulting biochar products. Our results show that the micrometer-scale pore structure of hybrid aspen biochars is not highly sensitive to clonal differences and within-tree heterogeneity. Of the studied factors (clone, ring, height, and pyrolysis), only pyrolysis (nonpyrolysed vs. pyrolysed samples) caused significant differences in the porosities, mean pore diameters in fibers, and fraction of pore volume in fibers/vessels. This demonstrates that in terms of micrometer-scale porosity, rather homogeneous biochar can be produced from a hybrid aspen feedstock even when there are significant differences in fiber properties (Fig. 5) and wood densities [18] between the clones and sampling locations. These findings support the idea of producing applicable and relatively homogeneous biochar products from hybrid aspen feedstocks. However, the mean pore diameters in vessels differed also by clone. Thus, biochar properties can be slightly optimized by choosing a clone with desired properties and the homogeneity of produced biochars can be increased by using only one clone in the production.

This study focused on the impacts of tree-trunk heterogeneity. Further studies assessing how branches, roots, and other components of the trees affect key biochar characteristics would be beneficial from the point of view of utilizing the whole biomass of hybrid aspen trees. Previously, Muigai et al. [40] showed how different components of various plants can have varying nano-scale pore properties. Furthermore, previously also wood density has been suggested to affect pore properties [14]. Biochar produced from different Eucalyptus species with different wood densities have been found to differ markedly in terms of water retention, with biochar from low density wood having a higher water retention capability than higher density wood [14]. The variation in wood density among the aspen clones at the site of the current study was rather small (334$422 \mathrm{~kg} \mathrm{~m}^{-3}$ [18]) and similar values (mean $362 \mathrm{~kg}$ $\mathrm{m}^{-3}$ ) have been reported from 32-year-old Finnish hybrid aspens [41]. These values are small compared to the study of Eucalyptus species by Werdin et al. (2020) $\left(572-960 \mathrm{~kg} \mathrm{~m}^{-3}\right)$. Werdin et al. [14] also suggested that wood density can be used as a proxy for biochar pore structure and that wood density is largely controlled by cell wall thickness and diameter, at least in a range of Eucalyptus species. The differences in the density ranges likely partly explain why the factors studied in the current study were not found to have a marked impact on biochar properties in contrast to the findings of Werdin et al. [14]. However, clearly speciesspecific factors such as a different ratio of cell wall thickness to diameter influenced the differences, since the wall thicknesses were around $1-2 \mu \mathrm{m}$ in the study of Werdin et al. [14], while they were around $6 \mu \mathrm{m}$ in the current study. On the other hand, wood density is largely controlled by cell wall thicknesses and diameters within different species [14, 42-45].

To understand how biochar properties are formed, it is central to know how cell wall thicknesses of feedstocks are transformed when pyrolysed. We showed that the cell wall thickness markedly decreased during the pyrolysis and that after the pyrolysis, the wall thicknesses did not statistically differ by their radial location (Fig. 3e). The highest cell wall thickness, located the closest to the bark (ring 1-2), decreased the most. Thus, it can be suggested that ratios of pyrolysed to non-pyrolysed wood porosities are higher in high density wood than in low density hybrid aspen wood. To our knowledge, differences between wall thicknesses of pyrolysed and non-pyrolysed wood samples have not been reported in previous studies. Furthermore, the correlation between the non-pyrolysed and pyrolysed individual samples (Fig. 4b) implies that feedstock cell wall thickness has controls on the wall thickness of the produced biochars.

\subsection{General discussion}

The highest differences in the fiber properties were found between the fiber lengths of the different radial locations (Fig. 5). The fiber characteristics were qualitatively similar to those found in previous studies $[42,46]$. Also DeBell et al. [46] showed an increasing trend in fiber lengths from pith to bark. The fiber widths did not markedly differ by ring, clone, or height in the current study (Fig. 5c).

While fiber characteristics have been previously reported, biochar cell wall thicknesses have been rarely measured. The reported correspondence between the wall thicknesses determined with the 3D image analyses and FiberLab fiber analyzer supports the usage of the rather novel image analysis methods to determine pore cell wall thicknesses. However, note also that the imaged wall thicknesses between the radial locations (rings) differed on average only $0.6 \mu \mathrm{m}$, which is smaller than the imaging resolution (voxel size $1 \mu \mathrm{m}$ ). Although the differences are deduced from changes in the wall thickness distribution, accurately detecting differences smaller than the imaging resolution could be partly inaccurate. In the current study, both the image analyses and FiberLab analyzer showed similar results regarding the differences between the rings, which gives confidence on the results. 
In previous studies, 3D image analysis methods have also been applied to study fiber wall thickness effects on contact area between the fibers in a pulp material [19]. Also, El Hachem et al. [47] determined cell wall thickness of spruce using X-ray tomography and reported average cell wall thicknesses of 6.3 and $5.1 \mu \mathrm{m}$ for latewood and earlywood, respectively. Regarding biochar applicability, information on pore wall thicknesses can be relevant regarding the potential of the feedstock to form pyrogenic (pyrolysis-induced) pores. Likely the pore wall thickness partly determines the potential of the biochar to contain pyrogenic pores (thick walls having a higher potential than thin walls). Note also that pyrogenic pores are typically nano-scale pores [12]. Even when the role of nano-scale pores in the total porosity and water retention is small $[8,11]$, their surface area and consequent impact on the sorption of different substances can be relatively high [12].

\section{Conclusions}

Our results showed how cell wall thickness dynamics had a central role in explaining how the pyrolysis increased the porosity of the samples despite the decreasing pore diameters. A larger decrease in the cell wall thicknesses than in the pore volumes explained the systematic increases in the porosities. Furthermore, wall thickness in the feedstock was shown to have controls on the resulting wall thickness of the biochar. Mechanistic understanding on pore property transformation during the thermal processing can help in predicting which raw materials are the most suitable for producing applicable biochars. Wall thicknesses and pore property transformation have had previously only a little attention. However, the process understanding can potentially benefit biochar design and studies regarding hybrid aspen wood can be extended to other feedstocks to reach more general conclusions.

Key pore properties of hybrid aspen biochar were found to be comparable with other wood-based biochars. Impacts of clonal differences and within-tree heterogeneity on biochar pore properties were shown to be small, but they can be of interest when planning how a forest biomass-based feedstock is utilized in biochar production. Based on the results, relatively homogeneous biochar can be produced from hybrid aspen wood despite of clonal differences and within-tree heterogeneity. The homogeneity of biochars can be further increased by using only one clone in the production. These findings suggest that hybrid aspen feedstock can be utilized to produce biochar for such end-uses which demand relatively homogeneous pore property quality.

\section{Appendix}
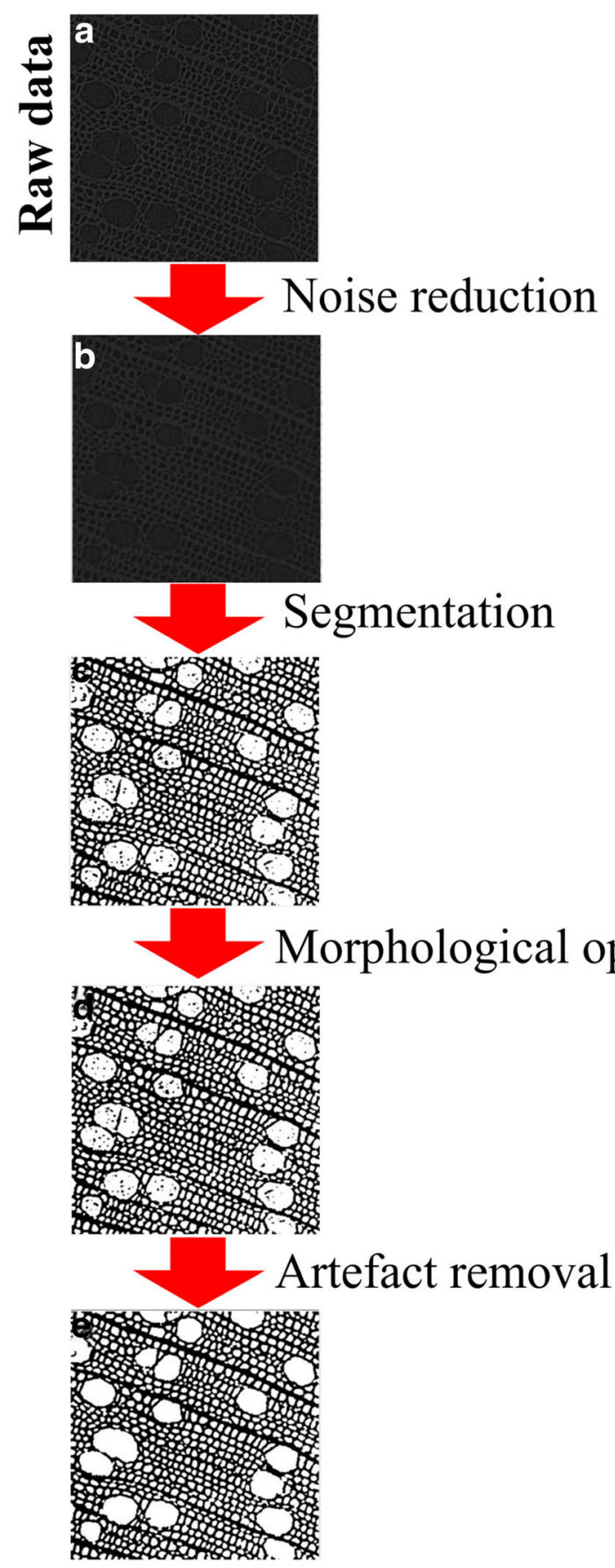

Fig. 6 A 2D visual representation of the image processing steps

Acknowledgements This study was funded by the Luke's strategic research funding to the projects 'More, faster, higher quality: potential of short-rotation aspen and willow biomass for novel products in bioeconomy' (AspenWill) and 'Added value potential of new and under-utilized fibre sources in Finnish value networks of green bioeconomy: prefeasibility, prototyping, and market acceptance' (VALUEPOT). We would like to thank Emmi Henriksson ( $\AA$ bo Akademi) for conducting the fiber analyses. 
Funding Open access funding provided by Natural Resources Institute Finland (LUKE). This study was funded by the Luke's strategic research funding to the projects 'More, faster, higher quality: potential of shortrotation aspen and willow biomass for novel products in bioeconomy' (AspenWill) and 'Added value potential of new and under-utilized fibre sources in Finnish value networks of green bioeconomy: prefeasibility, prototyping, and market acceptance' (VALUEPOT).

Availability of data and materials The authors do not wish to deposit the data.

Code availability The authors do not wish to deposit the codes.

\section{Declarations}

Conflict of interest The authors declare no competing interests.

Open Access This article is licensed under a Creative Commons Attribution 4.0 International License, which permits use, sharing, adaptation, distribution and reproduction in any medium or format, as long as you give appropriate credit to the original author(s) and the source, provide a link to the Creative Commons licence, and indicate if changes were made. The images or other third party material in this article are included in the article's Creative Commons licence, unless indicated otherwise in a credit line to the material. If material is not included in the article's Creative Commons licence and your intended use is not permitted by statutory regulation or exceeds the permitted use, you will need to obtain permission directly from the copyright holder. To view a copy of this licence, visit http://creativecommons.org/licenses/by/4.0/.

\section{References}

1. Ahmad M, Rajapaksha AU, Lim JE, Zhang M, Bolan N, Mohan D, Vithanage M, Lee SS, Ok YS (2014) Biochar as a sorbent for contaminant management in soil and water: a review. Chemosphere 99:19-33. https://doi.org/10.1016/j.chemosphere. 2013.10.071

2. Woolf D, Amonette JE, Street-Perrott FA, Lehmann J, Joseph S (2010) Sustainable biochar to mitigate global climate change. Nat Commun 1:1-9. https://doi.org/10.1038/ncomms1053

3. Edeh IG, Mašek O, Buss W (2020) A meta-analysis on biochar's effects on soil water properties-new insights and future research challenges. Sci Total Environ 714:136857. https://doi.org/10. 1016/j.scitotenv.2020.136857

4. Jeffery S, Meinders MB, Stoof CR, Bezemer TM, van de Voorde TF, Mommer L, van Groenigen JW (2015) Biochar application does not improve the soil hydrological function of a sandy soil. Geoderma 251:47-54. https://doi.org/10.1016/j.geoderma.2015. 03.022

5. Soinne H, Keskinen R, Heikkinen J, Hyväluoma J, Uusitalo R, Peltoniemi K, Velmala S, Pennanen T, Fritze H, Kaseva J, Hannula M (2020) Are there environmental or agricultural benefits in using forest residue biochar in boreal agricultural clay soil? Sci Total Environ 731:138955. https://doi.org/10.1016/j.scitotenv. 2020.138955

6. Turunen M, Hyväluoma J, Heikkinen J, Keskinen R, Kaseva J, Hannula M, Rasa K (2020) Quantifying the pore structure of different biochars and their impacts on the water retention properties of Sphagnum moss growing media. Biosyst Eng 191:96-106. https://doi.org/10.1016/j.biosystemseng.2020.01.006
7. Kameyama K, Miyamoto T, Iwata Y (2019) The preliminary study of water-retention related properties of biochar produced from various feedstock at different pyrolysis temperatures. Materials 12: 1732. https://doi.org/10.3390/ma12111732

8. Rasa K, Heikkinen J, Hannula M, Arstila K, Kulju S, Hyväluoma J (2018) How and why does willow biochar increase a clay soil water retention capacity? Biomass Bioenergy 119:346-353. https://doi. org/10.1016/j.biombioe.2018.10.004

9. Liu WJ, Jiang H, Yu HQ (2019) Emerging applications of biocharbased materials for energy storage and conversion. Energy Environ Sci 12:1751-1779. https://doi.org/10.1039/C9EE00206E

10. Brassard P, Godbout S, Raghavan V (2016) Soil biochar amendment as a climate change mitigation tool: key parameters and mechanisms involved. J Environ Manag 181:484 497. https://doi.org/ 10.1016/j.jenvman.2016.06.063

11. Hyväluoma J, Hannula M, Arstila K, Wang H, Kulju S, Rasa K (2018) Effects of pyrolysis temperature on the hydrologically relevant porosity of willow biochar. J Anal Appl Pyrolysis 134:446453. https://doi.org/10.1016/j.jaap.2018.07.011

12. Gray M, Johnson MG, Dragila MI, Kleber M (2014) Water uptake in biochars: the roles of porosity and hydrophobicity. Biomass Bioenergy 61:196-205. https://doi.org/10.1016/j.biombioe.2013. 12.010

13. Keskinen R, Hyväluoma J, Sohlo L, Help H, Rasa K (2019) Fertilizer and soil conditioner value of broiler manure biochars. Biochar 1:259-270. https://doi.org/10.1007/s42773-019-00020-7

14. Werdin J, Fletcher TD, Rayner JP, Williams NS, Farrell C (2020) Biochar made from low density wood has greater plant available water than biochar made from high density wood. Sci Total Environ 705:135856. https://doi.org/10.1016/j.scitotenv.2019.135856

15. Beuker E, Viherä-Aarnio A, Hynynen J (2016) Growth potential of first generation hybrid aspen plantations in Southern Finland. In: Poplars and other fast-growing trees - renewable resources for future green economies, International Poplar Commission, 25th session Berlin, Germany, 13-16 September 2016: Abstracts of submitted papers and posters. Working Paper IPC $14.118 \mathrm{p}$

16. Tullus A, Rytter L, Tullus T, Weih M, Tullus H (2012)Shortrotation forestry with hybrid aspen (Populus tremula L. $\times$ P. tremuloides Michx.) in Northern Europe. Scand J For Res 27:10 29. https://doi.org/10.1080/02827581.2011.628949

17. Hynynen J (1999) Haavan ja hybridihaavan kasvu ja tuotos. [Growth and yield of aspen and hybrid aspen]. In: Hynynen J., Viherä-Aarnio A. (eds.). Haapa - monimuotoisuutta metsään ja metsätalouteen. Vantaan tutkimuskeskuksen tutkimuspäivä Tammisaaressa 12.11.1998. Metsäntutkimuslaitoksen tiedonantoja 725, 25-37. http://urn.fi/URN:ISBN:951-40-1671-8. Accessed 20 Dec 2020

18. Hytönen J, Beuker E, Viherä-Aarnio A (2018) Clonal variation in basic density, moisture content and heating value of wood, bark and branches in hybrid aspen. Silva Fenn 52:9938. https://doi.org/10. 14214/sf.9938

19. Sormunen T, Ketola A, Miettinen A, Parkkonen J, Retulainen E (2019)X-ray nanotomography of individual pulp fibre bonds reveals the effect of wall thickness on contact area. Sci Rep 9:1-7. https://doi.org/10.1038/s41598-018-37380-2

20. Hytönen J, Beuker E, Viherä-Aarnio A (2020) Biomass allocation and nutrient content of hybrid aspen clones grown on former agricultural land in Finland. Scand J For Res 35:147-155. https://doi. org/10.1080/02827581.2020.1751269

21. Korkalo P, Korpinen R, Beuker E, Sarjala T, Hellström J, Kaseva J, Lassi U, Jyske T (2020) Clonal variation in the bark chemical properties of hybrid aspen: potential for added value chemicals. Molecules 25:4403. https://doi.org/10.3390/molecules25194403

22. Franklin GL (1945) Preparation of thin sections of synthetic resins and wood-resin compo-sites, and a new macerating method for wood. Nature 155:51. https://doi.org/10.1038/155051a0 
23. Schindelin J, Arganda-Carreras I, Frise E, Kaynig V, Longair M, Pietzsch T, Preibisch S, Rueden C, Saalfeld S, Schmid B, Tinevez JY (2012) Fiji: an open-source platform for biological-image analysis. Nat Methods 9:676-682. https://doi.org/10.1038/nmeth.2019

24. Rueden CT, Schindelin J, Hiner MC, DeZonia BE, Walter AE, Arena ET, Eliceiri KW (2017) ImageJ2: ImageJ for the next generation of scientific image data. BMC Bioinf 18:529. https://doi. org/10.1186/s12859-017-1934-z

25. Canny J (1986) A computational approach to edge detection. IEEE Trans Pattern Anal Mach Intell PAMI-8(6):679-698. https://doi. org/10.1109/TPAMI.1986.4767851

26. Ridler TW, Calvard S (1978) Picture thresholding using an iterative selection method. IEEE Trans Syst Man Cybern 8:630-632. https:// doi.org/10.1109/TSMC.1978.4310039

27. Legland D, Arganda-Carreras I, Andrey P (2016) MorphoLibJ: integrated library and plugins for mathematical morphology with ImageJ. Bioinformatics (Oxford Univ Press) 32(22):3532-3534. https://doi.org/10.1093/bioinformatics/btw413

28. Münch B, Holzer L (2008) Contradicting geometrical concepts in pore size analysis attained with electron microscopy and mercury intrusion. J Am Ceram Soc 91:4059-4067. https://doi.org/10.1111/ j.1551-2916.2008.02736.x

29. Svensson S, Borgefors G (2002) Digital distance transforms in 3D images using information from neighbourhoods up to $5 \times 5 \times 5$. Comput Vis Image Underst 88:24-53. https://doi.org/10.1006/ cviu.2002.0976

30. Gonzalez RC, Wood RE (2008) Digital image processing, 3rd edn. Prentice Hall, Upper Saddle River

31. Reyier Österling S, Ferritsius O, Ferritsius R (2012) The influence of fiber dimensions on mechanical pulp long fiber tensile index and density. Nord Pulp Pap Res J 27:844-859. https://doi.org/10.3183/ npprj-2012-27-05-p844-859

32. Kenward MG, Roger JH (2009) An improved approximationto the precision of fixed effects from restricted maximumlikelihood. Comput Stat Data Anal 53:2583e2595-2583e2595. https://doi. org/10.1016/j.csda.2008.12.013

33. Westfall PH (1997) Multiple testing of general contrasts usinglogical constraints and correlations. J Am Stat Assoc 92: 299e306. https://doi.org/10.2307/2291474

34. Standfest G, Kutnar A, Plank B, Petutschnigg A, Kamke FA, Dunky M (2013) Microstructure of viscoelastic thermal compressed (VTC) wood using computed microtomography. Wood Sci Technol 47:121-139. https://doi.org/10.1007/s00226-0120496-5

35. Schnee LS, Knauth S, Hapca S, Otten W, Eickhorst T (2016) Analysis of physical pore space characteristics of two pyrolytic biochars and potential as microhabitat. Plant Soil 408:357-368. https://doi.org/10.1007/s11104-016-2935-9

36. Brewer CE, Chuang VJ, Masiello CA, Gonnermann H, Gao X, Dugan B, Driver LE, Panzacchi P, Zygourakis K, Davies CA
(2014) New approaches to measuring biochar density and porosity. Biomass Bioenergy 66:176-185. https://doi.org/10.1016/j. biombioe.2014.03.059

37. Spokas KA, Weis R, Feyereisen G, Watts DW, Novak JM, Lim TJ, Ippolito JA (2016) Biomass or biochar - which is better at improving soil hydraulic properties? Acta Hortic 1146:235-242. https:// doi.org/10.17660/ActaHortic.2016.1146.31

38. Weber K, Quicker P (2018) Properties of biochar. Fuel 217:240 261. https://doi.org/10.1016/j.fuel.2017.12.054

39. Caguiat JN, Yanchus DS, Gabhi RS, Kirk DW, Jia CQ (2018) Identifying the structures retained when transforming wood into biocarbon. J Anal Appl Pyrolysis 136:77-86. https://doi.org/10. 1016/j.jaap.2018.10.020

40. Muigai HH, Bordoloi U, Hussain R, Ravi K, Moholkar VS, Kalita P (2021) A comparative study on synthesis and characterization of biochars derived from lignocellulosic biomass for their candidacy in agronomy and energy applications. Int J Energy Res 45:47654781. https://doi.org/10.1002/er.6092

41. Heräjärvi H, Junkkonen R (2006) Wood density and growth rate of European and hybrid aspen in Southern Finland. Balt For 12:2-8

42. Sable I, Grinfelds U, Zeps M, Irbe I, Noldt G, Jansons A, Treimanis A, Koch G (2013) Chemistry and kraft pulping of seven hybrid aspen clones. Dimension measurements on the vessels and UMSP of the cell walls. Holzforschung 67:505-510. https://doi.org/10. 1515/hf-2012-0184

43. Ziemińska K, Butler DW, Gleason SM, Wright IJ, Westoby M (2013) Fibre wall and lumen fractions drive wood density variation across 24 Australian angiosperms. AoB Plants 5:plt046. https://doi. org/10.1093/aobpla/plt046

44. Martínez-Cabrera HI, Jones CS, Espino S, Schenk HJ (2009) Wood anatomy and wood density in shrubs: responses to varying aridity along transcontinental transects. Am J Bot 96:1388-1398. https:// doi.org/10.3732/ajb.0800237

45. Fujiwara S, Sameshima K, Kuroda K, Takamura N (1991) Anatomy and properties of Japanese hardwoods I. Variation of fibre dimensions and tissue proportions and their relation to basic density. IAWA J 12:419-424

46. DeBell JD, Gartner BL, DeBell DS (1998) Fiber length in young hybrid Populus stems grown at extremely different rates. Can J For Res 28:603-608. https://doi.org/10.1139/x98-031

47. El Hachem C, Abahri K, Vicente J, Bennacer R, Belarbi R (2018) Hygromorphic characterization of softwood under high resolution X-ray tomography for hygrothermal simulation. Heat Mass Transf 54:2761-2769. https://doi.org/10.1007/s00231-018-2311-9

Publisher's Note Springer Nature remains neutral with regard to jurisdictional claims in published maps and institutional affiliations. 